\title{
PENYUSUTAN KALIUM IODAT DALAM GARAM BERYODIUM SELAMA PENYIMPANAN SUHU RENDAH
}

\author{
Reduction of Potassium Iodat in Iodized Salt at low temperature \\ Bahja, Wery Aslinda, Abnon Yesria \\ Politeknik Kesehatan Kemenkes Palu \\ (bahjadjamaluddin@gmail.com, no.telepon/Hp 085395265661)
}

\begin{abstract}
ABSTRAK
Kontribusi yodium dari makanan diperkirakan sebagian besar bergantung pada konsumsi garam beryodium. Kalium iodat $\left(\mathrm{KIO}_{3}\right)$ sering digunakan sebagai sumber yodium dalam garam beryodium, namun data eksperimen tentang stabilitas kalium iodat pada penyimpanan suhu rendah masih sangat terbatas. Penelitian ini bertujuan untuk menentukan pengaruh kondisi $\mathrm{KIO}_{3}$ garam beryodium yang disimpan pada suhu rendah $\left(0^{\circ} \mathrm{C}, 5^{\circ} \mathrm{C}, 13^{\circ} \mathrm{C}, 15^{\circ} \mathrm{C}\right.$, dan suhu rentang $\left.29-33^{\circ} \mathrm{C}\right)$. Penelitian ini merupakan jenis penelitian deskriptif, yang bertujuan untuk mengetahui kandungan $\mathrm{KIO}_{3}$ garam beryodium pada penyimpanan suhu rendah dengan mengunakan sampel garam yang dibeli dari pasar modern. Hasil yang diperoleh menunjukkan bahwa penyimpanan garam beryodium pada suhu rendah mengakibatkan penurunan kadar $\mathrm{KIO}_{3}$. Kehilangan $\mathrm{KIO}_{3}$ dalam garam beryodium cenderung meningkat jika suhu semakin rendah. Penyusutan kandungan $\mathrm{KIO}_{3}$ dalam garam beryodium pada penyimpanan suhu rendah yaitu: $0^{\circ} \mathrm{C}(17,4 \%), 5^{\circ} \mathrm{C}(7,3 \%), 13^{\circ} \mathrm{C}(6,8 \%), 15^{\circ} \mathrm{C}(2,4 \%)$ dan suhu rentang $29-33^{\circ} \mathrm{C}(2,3 \%)$. Berdasarkan hasil penelitian dapat disimpulkan bahwa kandungan $\mathrm{KIO}_{3}$ pada garam beryodium dapat mengalami penyusutan pada penyimpanan suhu rendah.
\end{abstract}

Kata kunci : Kalium iodat, garam beryodium, penyimpanan suhu rendah

\begin{abstract}
The contribution of iodine from food is thought to depend largely on the consumption of iodized salt. Potassium iodate $\left(\mathrm{KIO}_{3}\right)$ is often used as a source of iodine in iodized salt, but experimental data on the stability of potassium iodate at low temperature storage are still very limited. This study aims to determine the effect of $\mathrm{KIO}_{3}$ conditions of iodized salt stored at low temperatures $\left(0^{\circ} \mathrm{C}, 5^{\circ} \mathrm{C}, 13^{\circ} \mathrm{C}, 15^{\circ} \mathrm{C}\right.$, and a temperature range of $\left.29-33^{\circ} \mathrm{C}\right)$. This research is a descriptive type, which aims to determine the $\mathrm{KIO}_{3}$ content of iodized salt at low temperature storage using salt samples purchased from modern markets. The results obtained indicate that the storage at low temperatures of iodized salt resulted in a decrease in $\mathrm{KIO}_{3}$ levels. The loss of $\mathrm{KIO}_{3}$ in iodized salt tends to increase the lower the temperature. Depreciation of $\mathrm{KIO}_{3}$ content in iodized salt at low temperature storage, namely: $0^{\circ} \mathrm{C}(17.4 \%), 5^{\circ} \mathrm{C}(7.3 \%), 13^{\circ} \mathrm{C}(6.8 \%), 15^{\circ} \mathrm{C}(2.4 \%)$ and a temperature range of $29-33^{\circ} \mathrm{C}($ 2.3\%). Based on the results of the study, it can be concluded that the $\mathrm{KIO}_{3}$ content in iodized salt can experience shrinkage at low temperature storage.
\end{abstract}

Keywords : Potassium iodat, iodized salt, low temperature storage

\section{PENDAHULUAN}

Masalah gangguan Gizi Akibat Kekurangan Yodium (GAKY), masih banyak diderita penduduk Indonesia. Sekitar $11 \%$ penduduk Indonesia mengalami kekurangan yodium berat dan hasil ini dapat diperkuat dengan penelitian tentang pemetaan GAKY pada tahun 2003 yang menunjukkan peningkatan penderita GAKY dari 9,8\% menjadi 11,7\% pada tahun 2013 (Hariyanti \& Indrawati, 2013). 
Kekurangan yodium dalam tubuh menyebabkan hipertiroid, prevalensi hipertiroid tertinggi di Indonesia terdapat di DI Yogyakarta dan DKI Jakarta (masing-masing 0,7\%), Jawa Timur $(0,6 \%)$, dan Jawa Barat $(0,5 \%)$. Provinsi Sulawesi Tengah berada di urutan ke-4 yaitu sebanyak 0,4\% (Riset Kesehatan Dasar, 2013).

Pemerintah mendorong untuk berupaya menurunkan kejadian GAKY di Indonesia dengan memfortifikasi yodium pada garam dapur yang di konsumsi masyarakat. Tujuan utama fortifikasi yodium dalam garam untuk meningkatkan konsumsi yodium masyarakat sehari-hari. Fortifikan yodium dalam garam dapat berupa kalium iodida (KI) atau kalium iodat $\left(\mathrm{KIO}_{3}\right)$ (Permatasari, Helmiyati, \& Iskandar, 2017).

Produk garam beryodium yang bermutu harus sesuai dengan persyaratan Standar Nasional Indonesia SNI nomor 01-3556-2000, mengandung komponen utama natrium klorida 94,7\%, air maksimal 5\% dan kalium iodat mineral sebanyak 30 ppm serta senyawasenyawa lain sesuai persyaratan yang ditentukan. Yodium selain dapat diperoleh dari garam beryodium juga dapat diperoleh dari air minum, sayuran dan bahan makanan dari laut. Fortifikasi yodium dalam garam digunakan karena relatif murah dan terjangkau (Sugiani, Previanti, Sukrido, \& Pratomo, 2015).

Unsur yodium sangat mudah teroksidasi sehingga dalam penyimpanannya garam beryodium harus baik dan tidak disimpan di tempat yang akan mempengaruhi hilangnya yodium dalam garam beryodium. yodium bersifat sensitif terhadap panas dan cahaya. Proses pengolahan bahan makanan akan mengurangi ketersediaan yodium dalam makanan. Semakin tinggi suhu dan semakin lama waktu yang dipergunakan untuk mengolah bahan makanan maka semakin tinggi jumlah yodium yang hilang. Jumlah kebutuhan yodium tergantung dari umur dalam AKG pada kelompok bayi dan anak-anak 90$120 \mathrm{mcg}$, laki-laki remaja sampai lansia 120$150 \mathrm{mcg}$, dan perempuan remaja sampai lansia 120-150 mcg sedangkan untuk ibu hamil ditambah 70 mcg (Pusat Data dan Informasi, 2015). Kandungan yodium dalam makanan dapat susut akibat dari proses pemasakan yang salah dan menyebabkan absorbsi yodium rendah (Novitasari \& Muslimah, 2015).

Penelitian Novitasari \& Muslimah (2015) memaparkan bahwa yodium dapat mengalami penyusutan pada suhu panas dengan hasil jika kandungan yodium pada garam beryodium yang dipanaskan dalam suhu $60^{\circ} \mathrm{C}$ selama 5 menit mengalami penyusutan sebesar 12,8484 ppm, pada suhu $85^{\circ} \mathrm{C}$ dipanaskan selama 10 menit mengalami penyusutan sebesar 19,2672 ppm, kandungan yodium pada garam dapur beryodim yang dipanaskan pada suhu $95^{\circ} \mathrm{C}$ mengalami penyusutan sebesar 19,2672 ppm. Hasil penelitian yang senada juga menunjukkan bahwa kandungan yodium pada garam beryodium dalam wadah plastik transparan dan tidak transparan yang disimpan pada suhu $28^{\circ} \mathrm{C}$ selama 6 hari mengalami penyusutan kandungan yodium. Penyimpanan 
pada wadah transparan mengalami penurunan yodium rata-rata 9,49 ppm, sedangkan penyimpanan pada wadah plastik tidak transparan rata-rata mengalami penurunan kandungan yodium sebesar 4,99 ppm (Nurjaya, Aslinda, \& Astuti, 2019).

Penelitian yang telah dilakukan membuktikan bahwa suhu panas dan faktor wadah penyimpanan dapat menyusutkan kandungan yodium dalam garam dapur. Namun penderita GAKY masih sering ditemukan di daerah-daerah yang relatif bersuhu dingin. Berdasarkan data empiris penderita GAKY masih ditemukan di daerah pegunungan Kota Palu yaitu Kecamatan Lindu dan Kecamatan Kulawi sehingga peneliti ingin melihat apakah suhu dingin dapat berpengaruh terhadap kandungan $\mathrm{KIO}_{3}$ dalam garam beryodium yang dikonsumsi oleh masyarakat di daerah tersebut. Ditambah lagi, data eksperimen tentang stabilitas kalium iodat pada penyimpanan suhu rendah masih sangat terbatas.

Berdasarkan uraian diatas peneliti melakukan penelitian yang bertujuan untuk menganalisis kandungan $\mathrm{KIO}_{3}$ dalam garam beryodium pada penyimpanan suhu rendah $\left(0^{\circ} \mathrm{C}, 5^{\circ} \mathrm{C}, 13^{\circ} \mathrm{C}, 15^{\circ} \mathrm{C}\right.$, dan suhu rentang 29 $\left.33^{\circ} \mathrm{C}\right)$.

\section{METODE PENELITIAN}

Jenis penelitian pada penelitian ini adalah deskriptif, yang bertujuan untuk mengetahui kandungan kalium iodat $\left(\mathrm{KIO}_{3}\right)$ garam beryodium pada penyimpanan suhu rendah.
Sampel adalah garam beriodium yang diperoleh dari pasar modern. Kandungan kalium iodat dianalisis secara kuantitatif menggunakan metode titrasi Iodometri secara Duplo. Penelitian ini menggunakan alat-alat gelas yang umum digunakan dalam titrasi yakni neraca analitik, gelas arloji, spatula, biuret $50 \mathrm{~mL}$, statif, pipet skala $10 \mathrm{~mL}$, gelas kimia $250 \mathrm{~mL}$, erlenmeyer $250 \mathrm{~mL}$ serta bahan yang terdiri dari sampel garam beryodium, $\mathrm{Na}_{2} \mathrm{~S}_{2} \mathrm{O}_{3} 0,005 \mathrm{~N}$, Amilum $1 \%$, $\mathrm{H}_{2} \mathrm{SO}_{4} 2 \mathrm{~N}$, KI $20 \%$, dan Aquadest.

Sebelum disimpan, sampel garam diuji kandungan kalium iodat awalnya, kemudian dilakukan penyimpanan selama 1 minggu dalam keadaan terbuka. Penentuan kadar $\mathrm{KIO}_{3}$ pada garam sebelum dan setelah penyimpanan pada suhu dingin adalah sebagai berikut: sampel garam ditimbang sebanyak 10 gram dimasukan ke dalam erlenmeyer, ditambahkan $50 \mathrm{~mL}$ aquadest matang, kemudian ditambahkan $5 \mathrm{~mL}$ KI $20 \%$. Sebelum penambahan KI ditambahkan $2 \mathrm{~mL} \mathrm{H}_{2} \mathrm{SO}_{4} 2 \mathrm{~N}$ lalu erlenmeyer ditutup dan disimpan ditempat yang gelap selama 10 menit. Tutup erlenmeyer dibilas dengan aquadest agar $\mathrm{I}_{2}$ yang menguap keatas tutup erlenmeyer kembali kedalam erlenmeyer tersebut, kemudian ditambahkan amilum $1 \%$ sebanyak $1 \mathrm{~mL}$. Selanjutnya dititrasi dengan $\mathrm{Na}_{2} \mathrm{~S}_{2} \mathrm{O}_{3} \quad 0,005 \quad \mathrm{~N}$ (telah dilakukan standarisasi sebelumnya). Warna larutan akan berubah dari dari agak coklat tua gelap menjadi bening, volume titrasi dicatat. Kandungan kalium iodat dihitung menggunakan rumus sebagai berikut: 
Kadar $\mathrm{KIO}_{3}=\frac{1000}{\text { berat gram }} \times$ Volume titrasi $\mathrm{x} \frac{\mathrm{BM} \mathrm{KIO}_{3}(214)}{{\mathrm{Val} . \mathrm{KIO}_{3}(6)}_{0}} \times \mathrm{N} \mathrm{Na}_{2} \mathrm{~S}_{2} \mathrm{O}_{3}=\ldots \ldots \ldots$ ppm

\section{HASIL}

Sebelum dilakukan penyimpanan, sampel garam yang dibeli langsung dari pasar modern dilakukan pengecekan kandungan kalium iodat awal, kemudian dilakukan penyimpanan selama 1 minggu pada suhu rendah antara lain suhu $0{ }^{\circ} \mathrm{C}, \quad 5{ }^{\circ} \mathrm{C}, 13{ }^{\circ} \mathrm{C}, 15^{\circ} \mathrm{C}$ dan suhu kamar rentang $29-33^{\circ} \mathrm{C}$. Setelah penyimpanan selama 1 minggu dalam lemari pendingin yang disimpan dalam keadaan terbuka pada wadah plastik, selanjutnya dilakukan analisis kandungan $\mathrm{KIO}_{3}$ pada garam dapur. Hasil analisis kadar $\mathrm{KIO}_{3}$ serta persentasi penyusutan kadar $\mathrm{KIO}_{3}$ sebelum penyimpanan (minggu ke 0) dan setelah penyimpanan (minggu ke I) disajikan pada Tabel 1.

Tabel 1. Hasil Kadar $\mathrm{KIO}_{3}$

\begin{tabular}{cccccc}
\hline Minggu & \multicolumn{5}{c}{ Kadar KIO $_{\mathbf{3}}$ (ppm) } \\
\cline { 2 - 6 } $\mathbf{K e}$ & $\mathbf{0}^{\mathbf{0}} \mathbf{C}$ & $\mathbf{5}^{\mathbf{}} \mathbf{C}$ & $\mathbf{1 3}^{\mathbf{O}} \mathbf{C}$ & $\mathbf{1 5}^{\mathbf{}} \mathbf{C}$ & $\mathbf{2 9 - 3 3}^{\mathbf{}} \mathbf{C}$ \\
\hline 0 & 32,8 & 29,2 & 32,1 & 29,2 & 29,9 \\
I & 27,1 & 27,1 & 29,9 & 28,5 & 29,2
\end{tabular}

Sumber : Data Primer, 2020

Tabel 2. Persentasi Penyusutan Kadar $\mathrm{KIO}_{3}$ Persentasi Penyusutan Kadar $\mathrm{KIO}_{3}$

\begin{tabular}{ccccc}
\multicolumn{5}{c}{$(\%)$} \\
\hline $\mathbf{0}^{\mathbf{C}} \mathbf{C}$ & $\mathbf{5}^{\mathbf{C}} \mathbf{C}$ & $\mathbf{1 3}^{\mathbf{O}} \mathbf{C}$ & $\mathbf{1 5}^{\mathbf{C}} \mathbf{C}$ & $\mathbf{2 9 - 3 3}^{\mathbf{}} \mathbf{C}$ \\
\hline 17,4 & 7,3 & 6,8 & 2,4 & 2,3 \\
\hline
\end{tabular}

Sumber : Data Primer, 2020

\section{PEMBAHASAN}

Proses penentuan konsentrasi atau kadar $\mathrm{KIO}_{3}$ menggunakan wadah terbuka yang disimpan selama 1 minggu pada suhu rendah dilakukan secara kuantitatif menggunakan metode titrasi Iodometri. Berdasarkan volume titrasi yang diperoleh, dapat dicari konsentrasi
$\mathrm{KIO}_{3}$ dalam sampel yang dihitung menggunakan rumus. Larutan $\mathrm{Na}_{2} \mathrm{~S}_{2} \mathrm{O}_{3}$ yang digunakan telah distandarisasi sebelumnya.

Penentuan kandungan $\mathrm{KIO}_{3}$ dalam garam beriodium pada suhu rendah sangat bermanfaat untuk mengetahui pengaruh penyimpanan suhu rendah terhadap kehilangan kalium iodat pada garam beriodium. Hal ini terkait dengan daerah pegunungan yang memiliki suhu lingkungan yang relatif lebih rendah daripada daerah dataran.

Kalium iodida (KI) dan kalium iodat $\left(\mathrm{KIO}_{3}\right)$ biasanya digunakan sebagai fortifikan dalam garam beriodium, dimana masingmasing mengandung $77 \%$ dan $59 \%$ berat iodium. Sebagian besar negara dengan iklim tropis seperti di Indonesia menetapkan $\mathrm{KIO}_{3}$ sebagai fortifikan karena lebih stabil dalam kondisi penyimpanan dan distribusi.

Yodium dalam kalium iodat memiliki valensi positif 5 dan merupakan zat yang sangat oksidatif yang cenderung menarik elektron. Hal ini sejalan dengan fakta bahwa $\mathrm{KIO}_{3}$ tidak stabil dan dapat dengan mudah teroksidasi menjadi yodium oleh oksigen atau oksidator.

Dalam penelitian ini terlihat bahwa kadar $\mathrm{KIO}_{3}$ pada penyimpanan suhu rendah mengalami penyusutan. Semakin rendah suhu penyimpanan maka akan semakin kecil konsentrasi $\mathrm{KIO}_{3}$ dalam garam beryodium tersebut (Tabel 1) atau semakin besar persentasi penyusutannya (Tabel 2). Faktor yang mempengaruhi berkurangnya konsentrasi 
$\mathrm{KIO}_{3}$ tersebut disebabkan karena stabilitas penyimpanan $\mathrm{KIO}_{3}$ yang berkisar pada suhu 15 ${ }^{\circ} \mathrm{C}$ sampai dengan $25{ }^{\circ} \mathrm{C}$ (Chemicals \& Reagents., 2014-2016).

Penyusutan tersebut juga disebabkan karena garam disimpan di wadah terbuka yang memungkinkan terjadinya aliran udara sehingga $\mathrm{KIO}_{3}$ mudah mengalami oksidasi yang menyebabkan konversi iodat dalam garam beryodium menjadi iodida dan molekul yodium. Kondisi tersebut juga menyebabkan kelembaban relatif (RH) menjadi tinggi dimana RH yang tinggi dapat meningkatkan kadar air pada garam beryodium. Kadar air yang tinggi menyebabkan pelarutan $\mathrm{KIO}_{3}$. Penelitian sebelumnya menunjukkan bahwa kondisi kelembaban tinggi dan wadah penyimpanan yang memungkinkan terjadinya aliran udara berdampak terhadap kestabilan KI pada garam beryodium (Waszkowiak \& Szymandera-Buszka, 2008).

Potensi kehilangan yodium selama penyimpanan suhu rendah dapat terjadi sehingga untuk mengurangi kehilangan yodium selama distribusi, garam beryodium sebaiknya dikemas vakum dan disimpan dalam kondisi yang memadai, yaitu kelembaban rendah dan suhu yang sesuai dengan suhu penyimpanan.

\section{KESIMPULAN DAN SARAN}

Kadar $\mathrm{KIO}_{3}$ dalam garam beryodium menggunakan wadah terbuka yang disimpan selama 1 minggu pada suhu rendah mengalami penyusutan. Semakin rendah suhu penyimpanan maka akan semakin kecil konsentrasi $\mathrm{KIO}_{3}$ dalam garam beryodium tersebut atau persentasi penyusutan $\mathrm{KIO}_{3}$ semakin besar.

Perlu dilakukan penelitian lebih lanjut terkait penyusutan $\mathrm{KIO}_{3}$ pada penyimpanan dengan variasi kelembaban relatif (RH) menggunakan kemasan aluminium foil yang kedap udara.

\section{UCAPAN TERIMA KASIH}

Peneliti berterima kasih kepada Jurusan Gizi Politeknik Kesehatan Kemenkes Palu atas penyediaan fasilitas penelitian di Laboratorium Kuliner dan Laboratorium Terpadu Politeknik Kesehatan Kemenkes Palu.

\section{DAFTAR PUSTAKA}

1. Anonym. Riset Kesehatan Dasar. Jakarta: Kementerian Kesehatan RI; 2013.

2. Anonym. Chemicals \& Reagents. Germany: Merck Millipore. 2014-2016.

3. Anonym. Pusat Data dan Informasi. Jakarta: Kementerian Kesehatan RI. 2015.

4. Hariyanti, W., \& Indrawati, V. FaktorFaktor yang Mempengaruhi Kejadian GAKY pada Anak Usia Sekolah Dasar di Kecamatan Kendal Kabupaten Ngawi. Ejournal boga. 2013; Volume 2 Nomor 1: 150-158.

5. Novitasari, A. E., \& Muslimah, H. Pengaruh Suhu dan Waktu Pemanasan terhadap Kadar Kalium Iodat (KIO3) dalam Larutan Garam Beriodium. Jurnal Sains. 2015; Vol.5 No.10.

6. Nurjaya, Aslinda, W., \& Astuti, N. S.. Analisis Kandungan Yodium dalam Garam Beryodium pada Wadah Penyimpanan Plastik dan Kaca Selama 6 Hari Penyimpanan. Poltekita: Jurnal Ilmu Kesehatan. 2019;Vol 13 No 1: 25-29.

7. Permatasari, S. M., Helmiyati, S., \& Iskandar, S. Stabilitas Kadar Iodium dalam Garam Fortifikasi Kalium Iodida (KI) menggunakan NaFeEDTA. Darussalam Nutrition Journal. 2017;1(1):8-15.

8. Sugiani, H., Previanti, P., Sukrido, \& 
Pratomo, U. Penentuan Pengaruh Pemanasan dan Waktu Penyimpanan Garam Beriodium terhadap Kalium Iodat. Chimica et Natura Acta. 2015; Vol.3 No.2: 66-69.

9. Waszkowiak, K., \& Szymandera-Buszka, K.. Effect of storage conditions on potassium iodide stability in iodised table salt and collagen preparations. International Journal of Food Science and Technology. 2008;43:895-899 